\title{
Imaging of Hip Pain: From Radiography to Cross-Sectional Imaging Techniques
}

\author{
Fernando Ruiz Santiago, ${ }^{1}$ Alicia Santiago Chinchilla, ${ }^{2}$ \\ Afshin Ansari, ${ }^{3}$ Luis Guzmán Álvarez, ${ }^{1}$ Maria del Mar Castellano García, ${ }^{1}$ \\ Alberto Martínez Martínez, ${ }^{1}$ and Juan Tercedor Sánchez ${ }^{4}$ \\ ${ }^{1}$ Radiology Department, Hospital of Traumatology, Carretera de Jaen, S/N, 18014 Granada, Spain \\ ${ }^{2}$ Radiology Department, Ciudad Sanitaria Virgen de las Nieves, Avenida de las Fuerzas Armadas 2, 18014 Granada, Spain \\ ${ }^{3}$ Radiology Department, North Tyneside General Hospital, Rake Lane, North Shields NE29 8NH, UK \\ ${ }^{4}$ Orthopedic Department, Hospital of Traumatology, Carretera de Jaen, S/N, 18014 Granada, Spain
}

Correspondence should be addressed to Fernando Ruiz Santiago; ferusan12@gmail.com

Received 22 October 2015; Revised 17 December 2015; Accepted 20 December 2015

Academic Editor: Andreas H. Mahnken

Copyright (C) 2016 Fernando Ruiz Santiago et al. This is an open access article distributed under the Creative Commons Attribution License, which permits unrestricted use, distribution, and reproduction in any medium, provided the original work is properly cited.

\begin{abstract}
Hip pain can have multiple causes, including intra-articular, juxta-articular, and referred pain, mainly from spine or sacroiliac joints. In this review, we discuss the causes of intra-articular hip pain from childhood to adulthood and the role of the appropriate imaging techniques according to clinical suspicion and age of the patient. Stress is put on the findings of radiographs, currently considered the first imaging technique, not only in older people with degenerative disease but also in young people without osteoarthritis. In this case plain radiography allows categorization of the hip as normal or dysplastic or with impingement signs, pincer, cam, or a combination of both.
\end{abstract}

\section{Introduction}

In the last years, advancements in knowledge of biomechanics and hip joint functional anatomy, as well as improvements in arthroscopy procedures and refinements of imaging techniques, have widened the spectrum of diagnoses causing pain around the hip joint.

Radiologists, as part of the diagnostic team, have to know the appropriate use of different imaging techniques in order to reach an accurate diagnosis without delaying patient management.

\section{Causes of Hip Pain}

Causes of pain around the hip joint may be intra-articular, extra-articular, or referred pain from neighboring structures, such as sacroiliac joint, spine, symphysis pubis, or the inguinal canal [1].

Intra-articular causes include the following: labral tears, chondromalacia, degenerative changes, intra-articular bone injury, ligamentum teres rupture, arthritis (inflammatory, infectious, etc.), and synovial proliferative disorders.

Extra-articular causes include the following: tendinopathy, bursitis, iliotibial band syndrome, muscle injury, and piriformis syndrome.

This editorial review is going to focus mainly on intraarticular causes of hip pain.

\section{Hip Pain Imaging: Need for Clinical Correlation}

Imaging of the hip needs to be complementary to the clinical history and physical examination because it is well known that imaging findings do not always correlate with the presence of pain and vice versa.

Clinical tests are adapted to identify the source of pain as intra-articular or extra-articular. The flexion-abductionexternal rotation (FABER), internal range of motion with overpressure (IROP), and scour tests show sensitivity values 


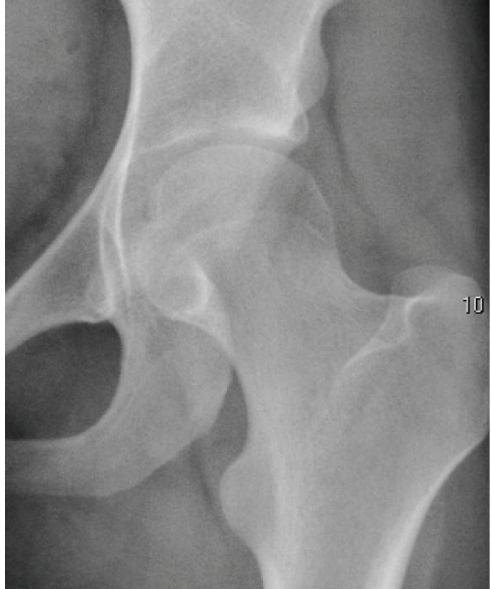

(a)

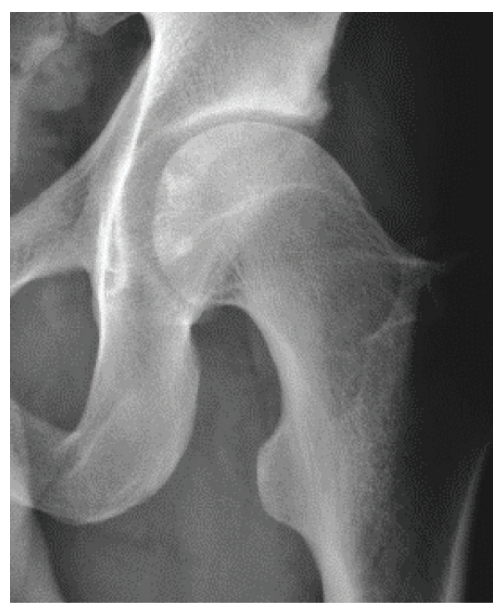

(d)

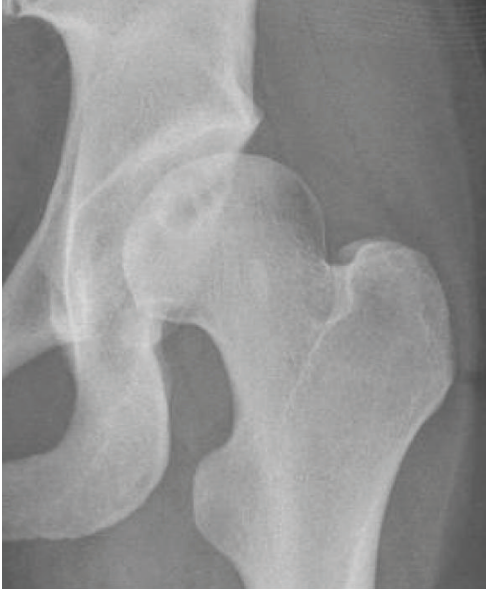

(b)

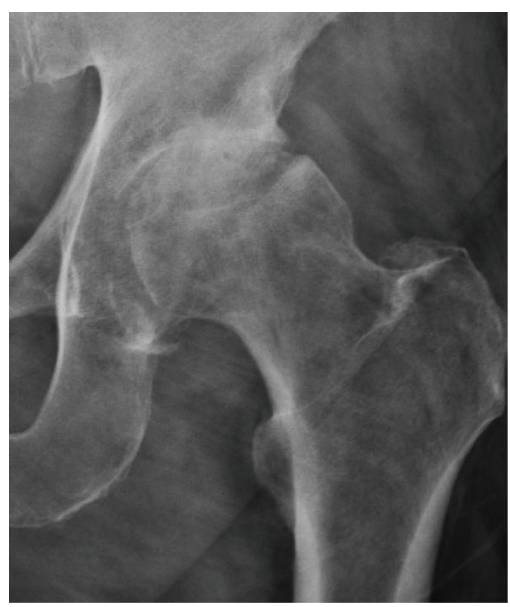

(e)

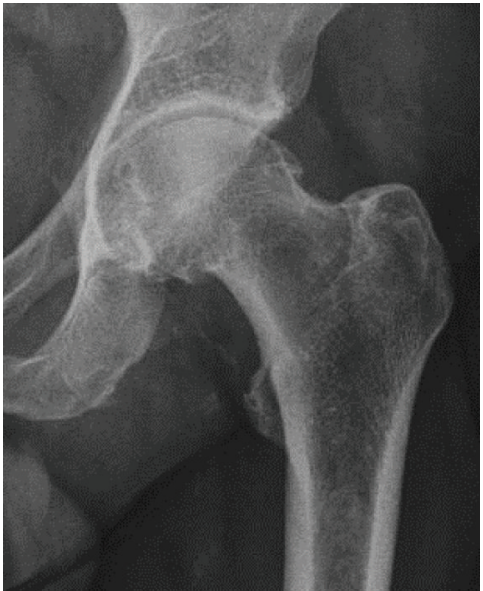

(c)

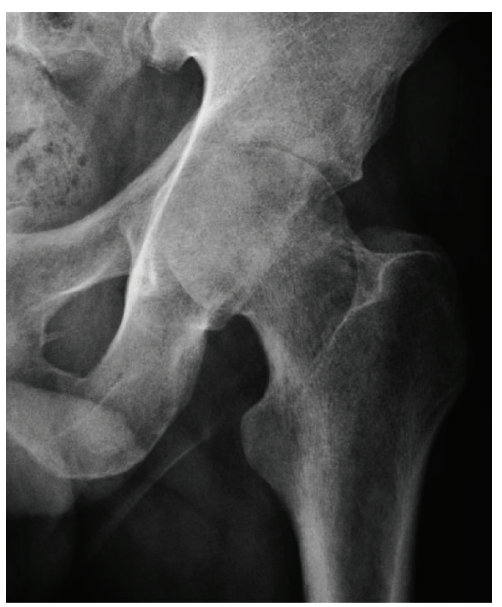

(f)

FIGURE 1: Radiography in normal hip (a), hip dysplasia (b), pincer impingement type (c), and cam (d). Hip in osteoarthritis (e) and septic arthritis (f).

in identifying individuals with intra-articular pathology ranging from 0.62 to 0.91 [2].

In the next subheadings, we are going to describe the main indications and role of different imaging modalities (Xray, magnetic resonance imaging (MRI), computed tomography (CT), ultrasound, and scintigraphy) in studying intraarticular causes of hip pain.

\section{X-Ray: A Basic Approach}

Radiographs are currently useful not only in older patients in whom osteoarthritis of the hip is suspected but also in younger patients without osteoarthritis, who are being evaluated for femoroacetabular impingement (FAI) or hip dysplasia.

Plain radiography allows us to categorize the hip as normal or dysplastic or with impingement signs (pincer, cam, or a combination of both). Besides these, pathologic processes like osteoarthritis, inflammatory diseases, infection, or tumors can also be identified (Figure 1).
4.1. X-Ray in Pediatric Age. Radiographs of infants should be obtained with the pelvis in neutral position with the lower limbs held in neutral rotation and slight flexion. Reliability of measurements increases if indicators of pelvic alignment are taken into account. Tönnis introduced a quotient of pelvic rotation by dividing the horizontal diameter of the obturator foramen of the right side and that of the left. In neutral rotation the ratio is 1 but is considered to be acceptable when it is between 0.56 and 1.8. The symphysis os-ischium angle of Tönnis evaluates the pelvic position in the sagittal plane. Lines are drawn from the highest point of the ischium to the most prominent point of the symphysis, joining at the inside of the pelvis. The range of normal values is from 90 to $135^{\circ}$ and is related to the infant's age [3].

Despite the widespread of ultrasound, pelvis radiographs are still frequently used to diagnose and/or monitor DDH or for assessing other congenital conditions or bone tumors [4]. The Tönnis method is the most widely used radiographic system to classify DDH [5]. It relies on the presence of the femoral head ossification center. Because eccentric position 


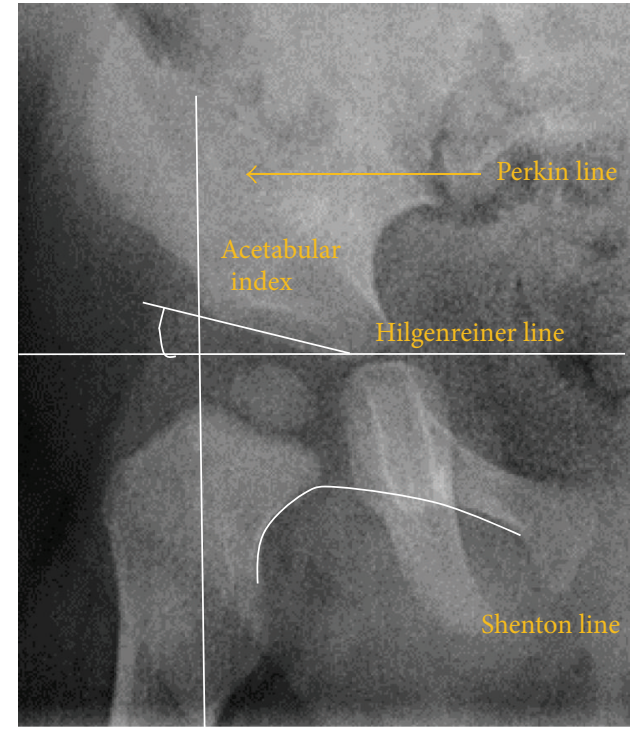

(a)

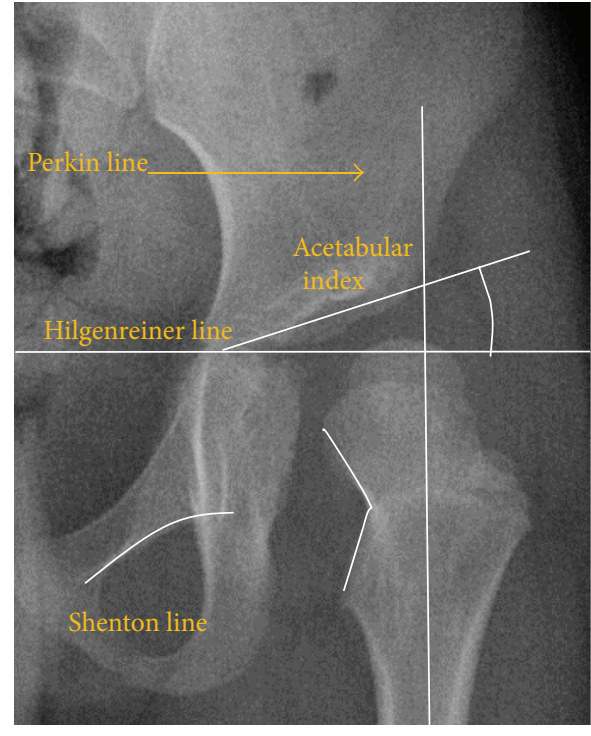

(b)

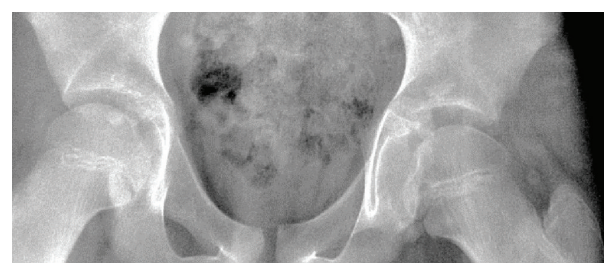

(c)

FIGURE 2: Radiological measurements in pediatric normal (a) and dysplastic hip (b). (c) AP view of a patient with left hip effusion secondary to trauma showing widening of the medial joint space.

or delayed appearance of the ossific nucleus is a common finding in DDH, a new radiographic classification system has been developed by the International Hip Dysplasia Institute (IHDI), which uses the mid-point of the proximal femoral metaphysis as a reference landmark [6].

The most useful lines and angles that can be drawn in the pediatric pelvis assessing DDH are shown in Figure 2.

(A) Hilgenreiner Line. It is considered a basal line joining the top aspect of the triradiate cartilages. This line is used to measure the acetabular angle and as a reference for Perkin line.

(B) Perkin line is perpendicular to Hilgenreiner line, touching the lateral margin of the acetabulum. This leads to four quadrants and a normal femoral head has to be located in the inferomedial quadrant. We can measure the lateral displacement of the femoral head with regard to the Perkin line by dividing the width of the head that crosses the Perkin line by the diameter of the head. The value for patients under 3 years must be 0 and in older children this ranges from 0 to $22 \%$.

(C) Shenton line is a continuous arc drawn from the inner edge of the femoral neck to the superior margin of the obturator foramen. This should be smooth and undisrupted; otherwise it may indicate a fracture or hip dysplasia.
(D) The acetabular index measures the acetabular roof slope. It is the most useful measure of acetabular dysplasia until 6 years of age. It is formed between Hilgenreiner line and the acetabular roof. In newborns, values of $26^{\circ} \pm 5^{\circ}$ in males and $30^{\circ} \pm 4^{\circ}$ in females are considered normal. Gradually this angle becomes smaller, with a mean value of $18^{\circ} \pm 4^{\circ}$ in males and $20^{\circ} \pm 3^{\circ}$ in females at 1 year of age [7].

(E) The medial articular joint space is measured between the medial border of the femoral head or neck (when epiphysis is not ossified) and the acetabular platform. Normal values range between 5 and $12 \mathrm{~mm}$. Differences greater than $1.5 \mathrm{~mm}$ between the two sides are considered abnormal [8].

Most cases of Legg-Calvé-Perthes disease (LCPD) develop between the ages of 4 and 10 years (Figure 3). Classification of its severity can be assessed by radiographs. Herring or lateral pillar classifications and the patient's age strongly correlate with the outcome [9]. In Group A, which has a better prognosis, there are no loss of height in the lateral third of the femoral head and little density changes; in Group B, there is lucency and lateral height loss of less than 50\%; and in Group $\mathrm{C}$, the most severe form, there is more than $50 \%$ loss of lateral height. Group B/C is considered when the loss of lateral pillar height is at $50 \%$ [10]. Patients who are over the age of 8 years 


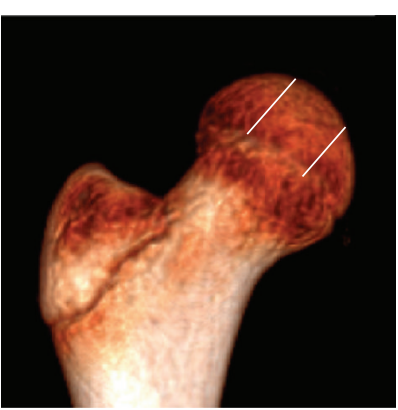

(a)

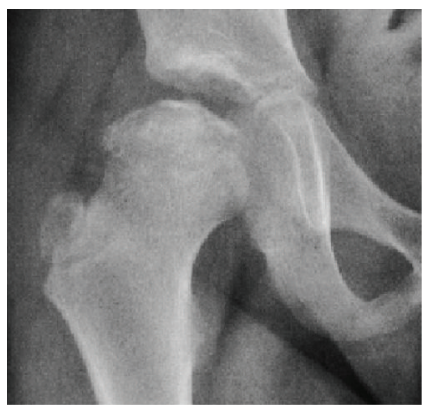

(e)

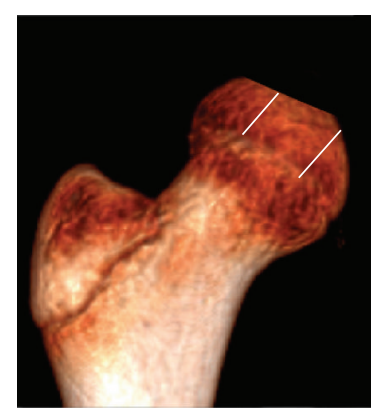

(b)

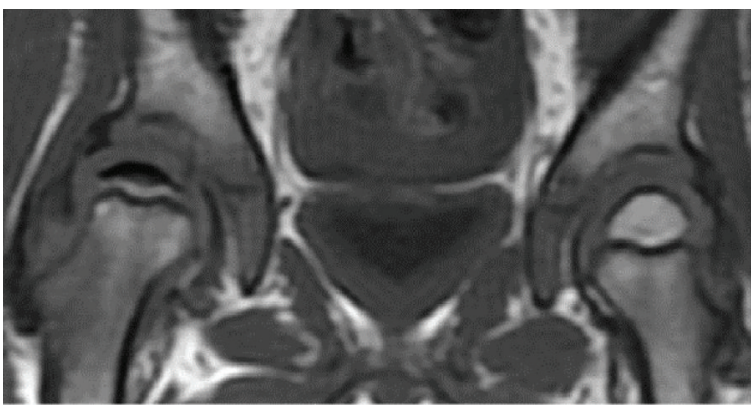

(f)

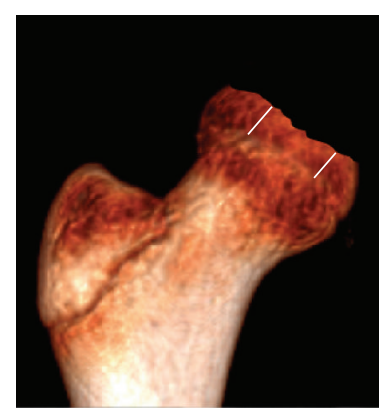

(c)

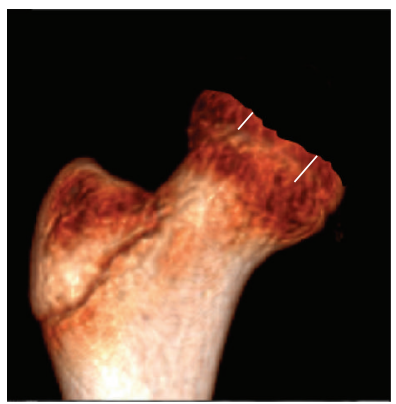

(d)

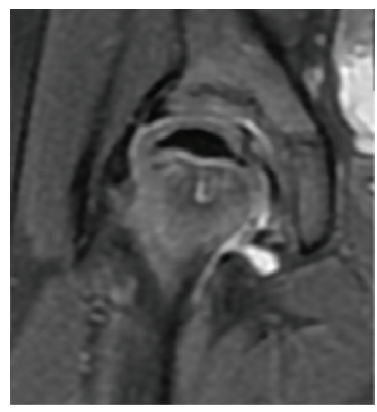

(g)

Figure 3: Herring lateral pillar classification. Groups A (a), B (b), B/C (c), and C (d). AP radiograph (e), coronal T1 (f), and PD fat sat (g) weighted images showing loss of fat signal of the epiphysis, edema, and cyst formation in femoral metaphysis in a grade $\mathrm{C}$ Perthes disease.

at the time of onset and have a hip in the lateral pillar B group or $\mathrm{B} / \mathrm{C}$ border group have a better outcome with surgical treatment than they do with conservative treatment. Group B hips in children who are less than 8 years at the time of onset have a very favorable outcome unrelated to the treatment, whereas Group C hips in children of all ages usually have poor outcome unrelated to the treatment [11].

Slipped Capital Femoral Epiphyses (SCFE) usually affect 11- to 14-year-old patients (Figure 4). Radiographs may show widening and irregularity of the physis and posterior inferior displacement of the capital femoral epiphysis. On the AP view Klein's line, tangent to the lateral aspect of the femoral neck, does not intersect the femoral head indicating that it is displaced. SCFE may compromise the blood supply to the femoral head and cause avascular necrosis, mainly when there is instability between the fragments [12].

4.2. X-Ray in Adult Age. In the adult hip there are important landmarks to be recognized on plain film radiographs (Figure 5):

(A) Iliopectineal or iliopubic line is formed by the arcuate line of the ilium and the superior border of the superior pubic ramus up to the pubic symphysis. It conforms to the inner margin of the pelvic ring and it is part of the anterior column of the acetabulum.

(B) The ilioischial line of Köhler begins at the medial border of the iliac wing and extends along the medial border of the ischium to end at the ischial tuberosity. It is part of the posterior column of the acetabulum.
(C) Acetabular Floor. In normal conditions the floor of the acetabular fossa is lateral to the ilioischial line by $2 \mathrm{~mm}$ in men and $1 \mathrm{~mm}$ in women. When the acetabular floor overlaps or overpasses the ilioischial line, the diagnosis of coxa profunda can be made. Nevertheless, coxa profunda had been found in $76 \%$ of asymptomatic hips, mainly in women. Therefore, this as an isolate criterion is not enough to make the diagnosis of pincer-type impingement [13]. A more severe condition is protrusio acetabuli, diagnosed when the femoral head overlaps or overpasses the ilioischial line (Figure 5).

(D) The teardrop represents a summation of shadows. Its medial aspect corresponds to the inner cortex of the pelvis and the lateral edge with the acetabular notch and the anteroinferior portion of the quadrilateral plate [14]. It is not present at birth but gradually develops due to pressure of the femoral head.

In the adult hip, normal joint space ranges from 3 to $5 \mathrm{~mm}$ and must be uniform. Values under $2 \mathrm{~mm}$ are consistent with joint space narrowing [15]. The most important measurements are detailed in Figure 6 and Table 1.

Acetabular depth value under 250 characterizes the dysplastic hip [16].

In normal conditions the acetabulum covers $75 \%$ of the femoral head. This coverage can be determined by three different measurements: lateral center-edge angle of Wiberg, anterior center-edge angle, and femoral extrusion index. Femoral extrusion index measures the percentage of 
TABLE 1: Measurements in adult hip.

\begin{tabular}{|c|c|c|}
\hline Measurement & Measure & Normal value \\
\hline Acetabular depth ratio & Deepness of acetabulum & $>250$ \\
\hline Center-edge angle & Coverage of acetabulum & $20-40$ \\
\hline Tönnis angle & Slope of the sourcil & $0-10^{\circ}$ \\
\hline Sharp angle & Acetabular slope & $<45^{\circ}$ \\
\hline Crossing ratio & Percentage of acetabular walls crossing & $<20 \%$ \\
\hline Alpha angle & Degree of bulging of the femoral head-neck junction & $\begin{array}{c}\text { Male }>68^{\circ} \\
\text { Female }>50^{\circ}\end{array}$ \\
\hline Femoral head-neck offset & Offset of the femoral head with regard to most prominent aspect of the femora neck & $>10 \mathrm{~mm}$ \\
\hline Offset percentage & Femoral head-neck offset related to femoral head diameter & $>0.18$ \\
\hline
\end{tabular}

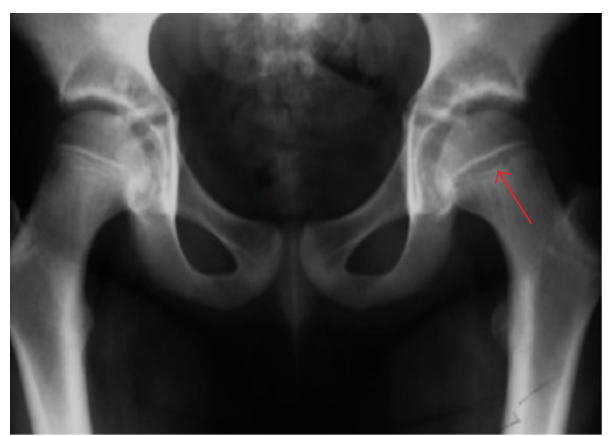

(a)

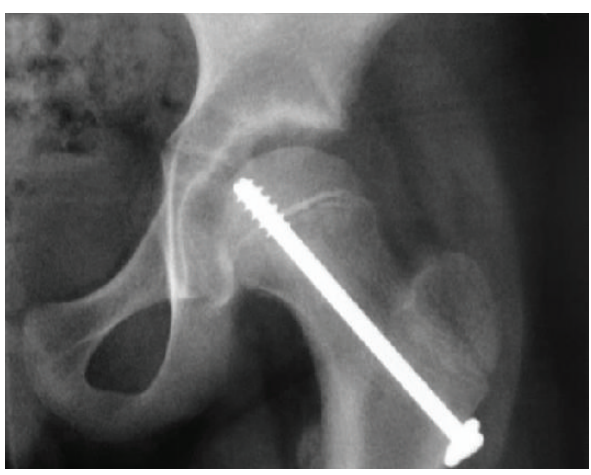

(c)

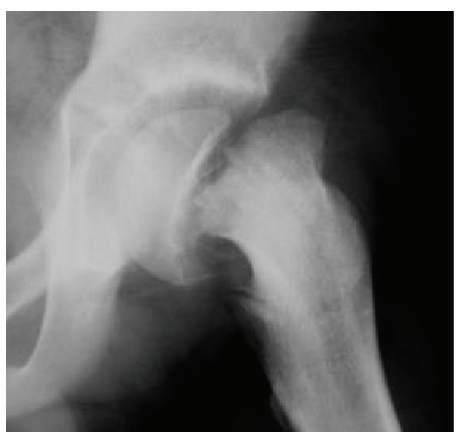

(b)

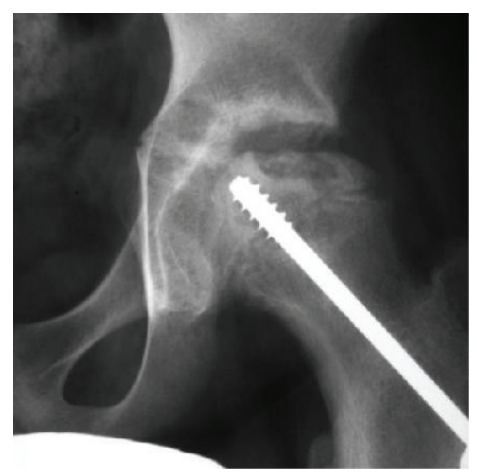

(d)

Figure 4: (a) X-ray of a 10-year-old child with left hip pain. It was considered normal at emergency despite the widening of the left physis (arrow). Two weeks later epiphysiolysis was evident (b). Despite appropriate surgical reduction (c) osteonecrosis developed and femoral head collapsed 1 month later (d).

the femoral head that lies outside of the acetabular roof. This percentage must be inferior to $25 \%$ in adults.

Center-edge Wiberg's angle measures the superior-lateral coverage of the femoral head. It is useful in children older than 5 years and in adulthood. For children between 5 and 10 years the minimum normal value is $15^{\circ}$, and in adults it is about $20^{\circ}$, although after 55 years this minimum increases to $24^{\circ}$ [17]. Values over $40^{\circ}$ indicate overcoverage.

Anterior center-edge Lequesne's angle can be measured in a false profile view of the hip or in a sagittal CT scan. In this case the tangent line touches the anterior rim of the acetabulum. Values under $20^{\circ}$ indicate undercoverage of the femoral head [18].
The acetabular slope can also be measured by different methods. The Tönnis angle quantifies the slope of the sourcil (the sclerotic weight-bearing portion of the acetabulum). Values over $10^{\circ}$ are considered a risk factor for instability, while values under $0^{\circ}$ are considered a risk factor for pincer impingement.

The Sharp angle is a global way to measure the acetabular slope. Angles over $45^{\circ}$ are indicative of acetabular dysplasia.

Normal acetabulum is oriented in anteversion. Its value ranges from 15 to $20^{\circ}$ in the equatorial plane of the acetabulum and decreases gradually towards the acetabular roof, where normal values range from 0 to $5^{\circ}$. Retroversion of the upper part of the acetabulum has been related with 


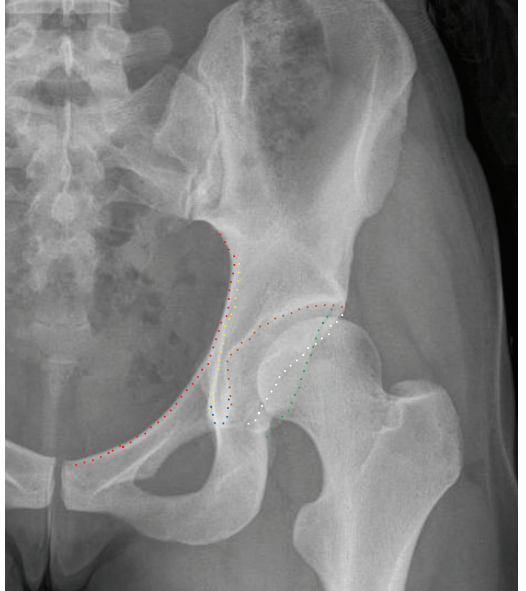

(a)

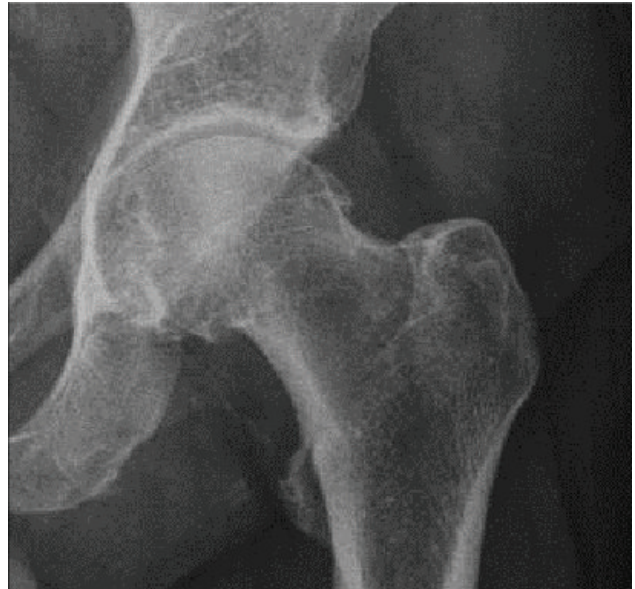

(b)

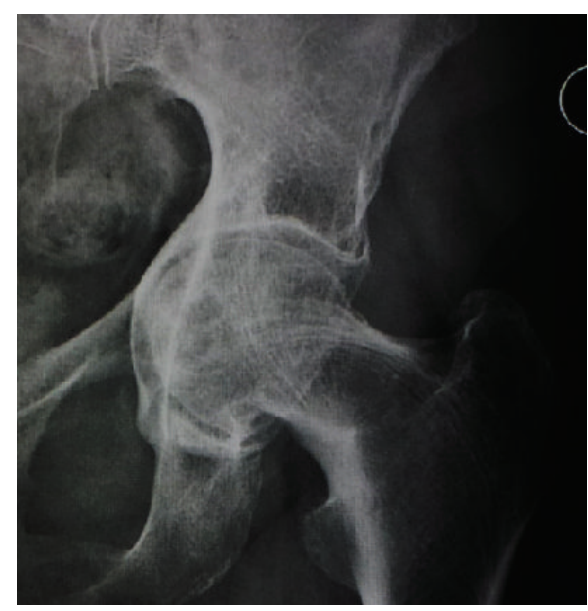

(c)

Figure 5: (a) Iliopectineal line (red), ilioischial line (yellow), tear drop (blue), acetabular fossa (brown), and anterior (white) and posterior (green) wall of the acetabuli showing mild upper crossover sign. (b) Coxa profunda. (c) Protrusio acetabuli.

pincer type impingement. In radiography the presence of a "crossover sign" is produced when the posterior wall of the acetabulum crosses the anterior wall before reaching the acetabular roof. It is a sign of acetabular retroversion and it has been linked with overcoverage and pincer impingement. Nevertheless, this sign has been described in $6 \%$ of the normal population [19]. Therefore, more important than its presence is the percentage of crossing. This ratio is considered significant if it is over $20 \%$ [20].

Other signs associated with acetabular retroversion are the sciatic spine and posterior wall signs. The first one is considered positive when the sciatic spine is projected medial to the iliopectineal line in an AP radiography of the spine, indicating that it is not just the acetabulum but the whole hemipelvis that is twisted into retroversion. The second sign is considered positive when the posterior wall edge is medial to the center of the femoral head, indicating deficiency of the posterior wall.

In normal conditions there is a symmetric concave contour at the junction of the anterior and posterior profile of the femoral head and neck. Loss of this concavity or bone bulging may lead to cam type impingement. The degree of this deformity can be measured by the alpha angle. Although it can be measured in the cross-lateral view, the $45^{\circ}$ Dunn view is considered more sensitive and the frog leg view more specific in determining pathologic values. Debate about which values are considered normal is still in progress. Based on the Copenhagen Osteoarthritis Study, a recent work defined three ranges of values for the $\alpha$-angle: pathological ( $\geq 83^{\circ}$ in men and $\geq 57^{\circ}$ in women), borderline $\left(69^{\circ}\right.$ to $82^{\circ}$ in men, $51^{\circ}$ to $56^{\circ}$ in women), and normal $\left(\leq 68^{\circ}\right.$ in men and $\leq 50^{\circ}$ in women) [21].

The offset between the neck and femoral head can also be calculated in the lateral projection of the hip. A value of less than $10 \mathrm{~mm}$ is considered pathologic. The percentage is calculated by dividing the distance between the femoral head and the neck lines by the femoral head diameter. If this percentage is under 0.18 there is high probability of cam type impingement [22]. 


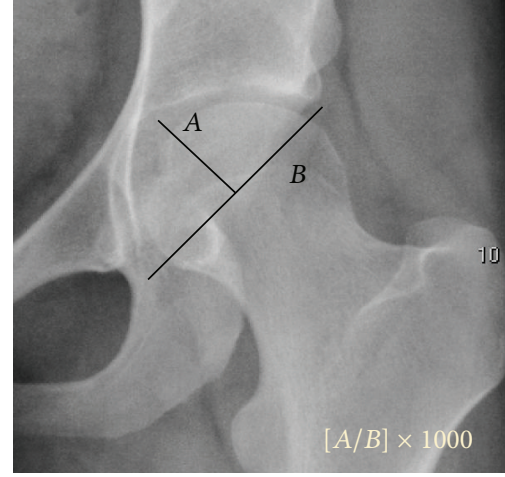

(a)

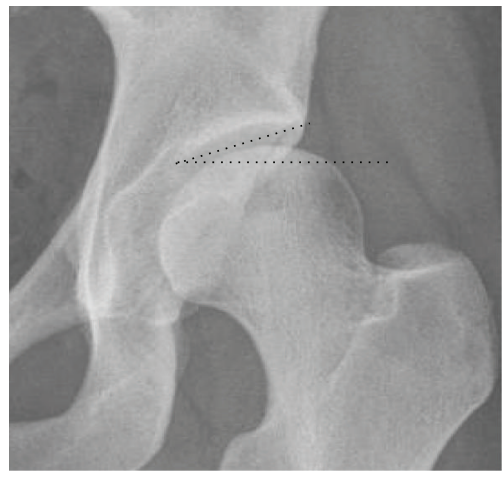

(d)

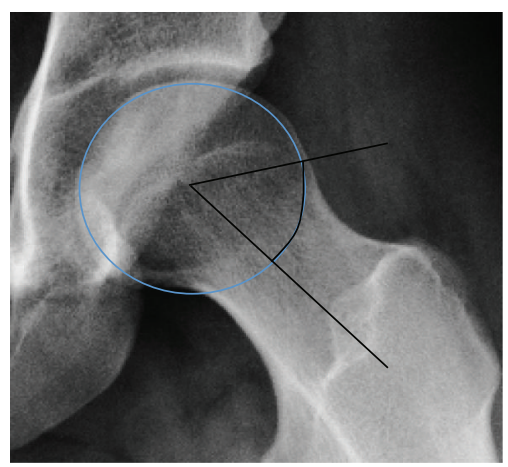

(g)

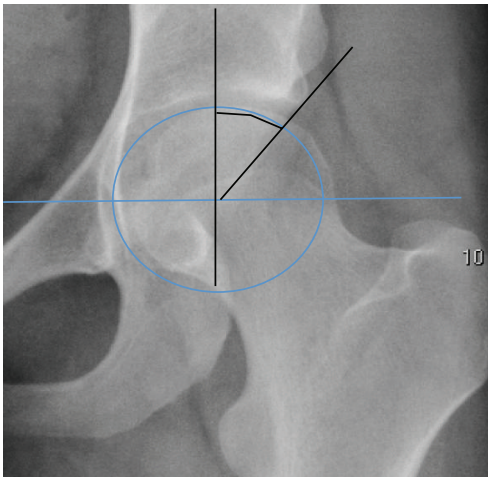

(b)

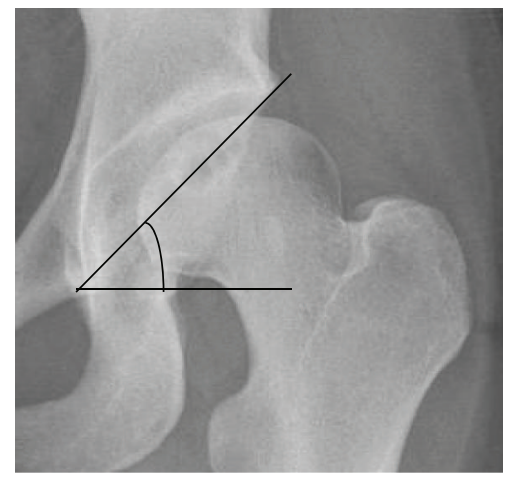

(e)

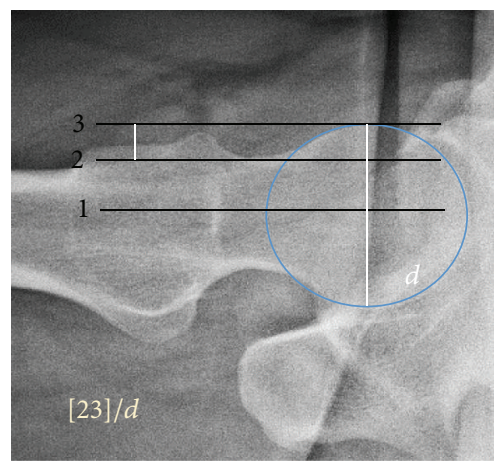

(h)

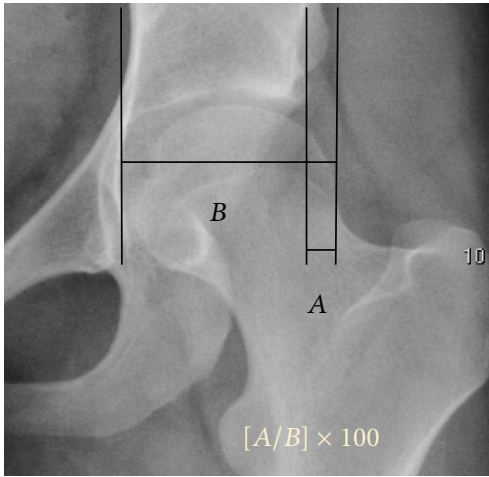

(c)

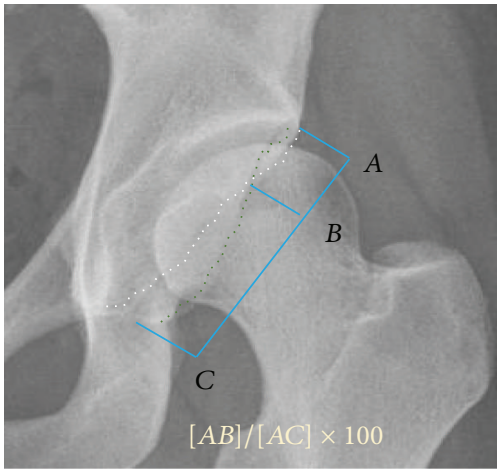

(f)

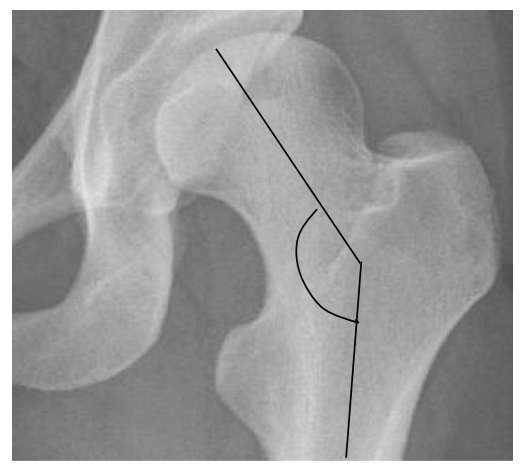

(i)

Figure 6: (a) Acetabular depth ratio. (b) Center-edge angle of Wiberg. (c) Femoral extrusion index. (d) Tönnis angle. (e) Sharp angle. (f) Crossing ratio. (g) Alpha angle measured in $45^{\circ}$ Dunn view. (h) Offset percentage measured in cross-lateral view. (i) Cervical diaphyseal angle.

The angle formed between the femoral neck and femoral diaphysis ranges from $120^{\circ}$ to $140^{\circ}$. Coxa valga is diagnosed if the angle is higher and coxa vara if the angle is lower than this normal range.

Although femoral version or torsion can be measured by radiographs, CT overcomes the inconsistencies demonstrated in the measurements made by biplane radiography [23].

In adults, one of the main indications for radiographs is the detection of osteoarthritic changes (Figure 1(e)). Nevertheless, radiographs usually detect advanced osteoarthritis that can be graded according to the Tönnis classifications. The grading system ranges from 0 to 3 , where 0 shows no sign of osteoarthritis. Intermediate grade 1 shows mild sclerosis of the head and acetabulum, slight joint space narrowing, and marginal osteophyte lipping. Grade 2 presents with small cysts in the femoral head or acetabulum, moderate joint space narrowing, and moderate loss of sphericity of the femoral head. Grade 3 is the severest form of osteoarthritis, which manifests as severe narrowing of the joint space, large subchondral cyst with productive bone changes that may lead to deformity of the bone components of the joint [24], while secondary osteoarthritis due to calcium pyrophosphate deposition can be diagnosed when calcification of hyaline cartilage and fibrocartilage is detected [25].

There are other pathological conditions that can affect the hip joint and radiographs help to make the appropriate diagnosis. Acute bacterial septic arthritis can be diagnosed by 


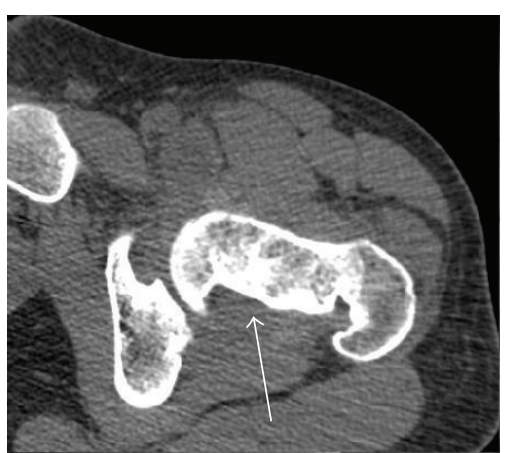

(a)

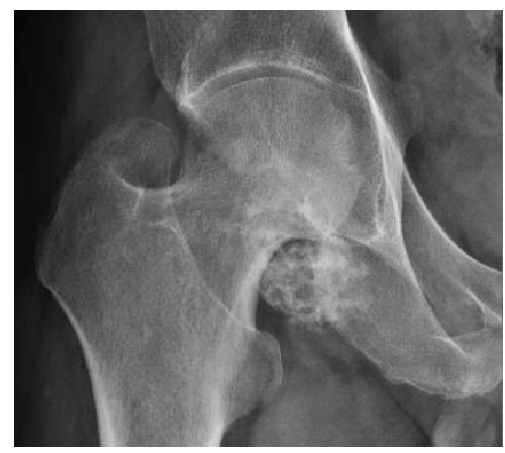

(c)

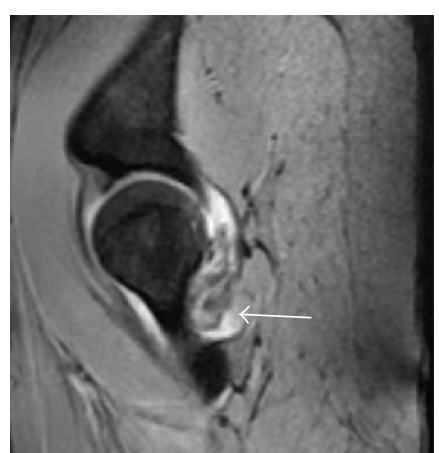

(b)

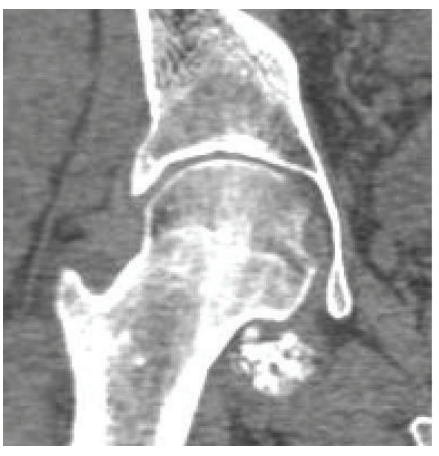

(d)

Figure 7: (a) Axial CT image of pigmented villonodular synovitis eroding the posterior cortex of the femoral neck. (b) Sagittal T2* gradient echo image showing a posterior soft tissue mass with hypointense areas secondary to hemosiderin deposition. (c) X-ray film and computed tomography (d) in synovial chondromatosis.

radiographs when a fast regional osteoporosis and destructive monoarticular process develops (Figure 1(f)). In case of tuberculous or brucella arthritis it is manifested as a slow progressive process, and diagnosis may be delayed [26].

Synovial chondromatosis can be confidently diagnosed by X-ray when calcified cartilaginous chondromas are seen. However, other synovial proliferative processes, such as pigmented villonodular synovitis, require MRI for accurate diagnosis, although noncalcified synovitis can be suspected in radiographs by indirect signs, such as soft tissue swelling and/or erosions in the femoral head, femoral neck, or acetabulum (Figure 7) [27].

Radiological signs of transient osteoporosis of the hip include localized osteoporosis of the femoral head and neck (Figure 8). Nevertheless, final diagnosis has to be made with MRI to differentiate it from avascular necrosis and from insufficiency or stress fractures of the femoral head or neck. In case of AVN, radiographs can only demonstrate delayed or advanced signs. Staging according to Ficat classification ranges between normal appearance (stage I), slight increased density in the femoral head (stage II), subchondral collapse of the femoral head with or without "crescent" sign (stage III), and advanced collapse with secondary osteoarthritis (stage IV) [28]. In the case of stress or insufficiency fractures Xray sensitivity has been proven to be much lower than MRI, which is currently the gold standard [29].

\section{Magnetic Resonance}

Many pathological conditions of the hip are detected early by MRI due to its high soft tissue resolution and sensitivity. Its accuracy in studying acute hip pain in children has proved to be superior to ultrasound and plan film radiography. However, MRI accessibility and the need of sedation relegate its use to selected cases in which diagnosis is not clear with less demanding techniques. These include differentiating transient synovitis from a septic arthritis or osteomyelitis [30], diagnosis of inflammatory joint disease or bone tumors, and early detection and follow-up of Perthes disease.

MRI findings correlate with prognosis in LCPD. These include extent and distribution of epiphyseal necrosis, subchondral ossified nucleus fracture, involvement of the lateral pillar, and disturbance of physeal growth, including presence of transphyseal neovascularity or bridging [31].

Recent studies have been focused on the role of diffusion weighted MRI because it does not need contrast medium administration. ADC ratio of the femoral metaphysis was positively correlated with the Herring classification. ADC ratio superior to 1.63 indicates bad prognosis with $89 \%$ sensitivity and $58 \%$ specificity [32].

In adult patients, MRI is currently playing a definite role in the assessment of osteoarthritis. Although traditionally belonging to the arena of radiographs, the role of MRI has 


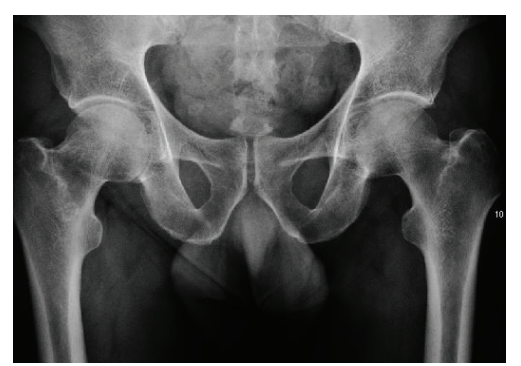

(a)

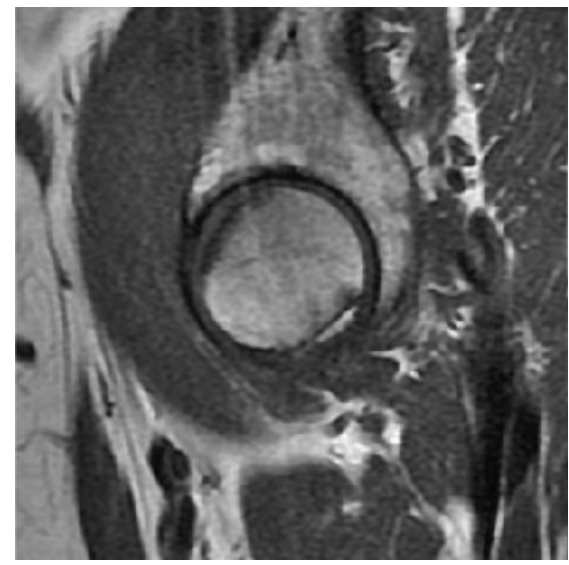

(d)

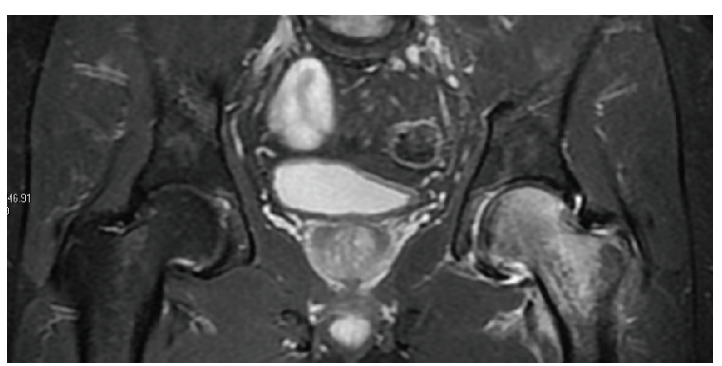

(b)

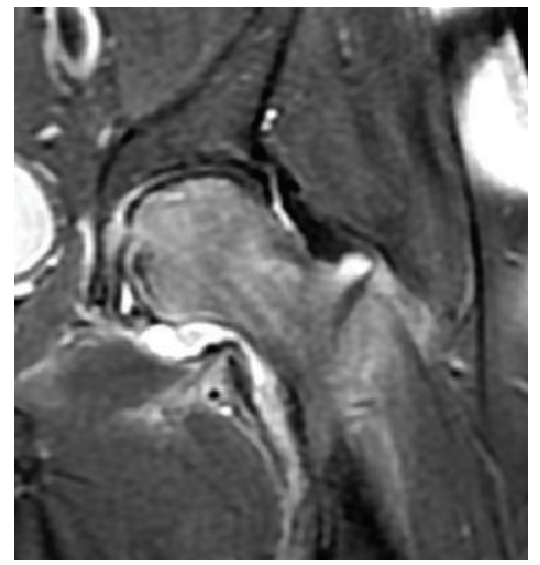

(e)

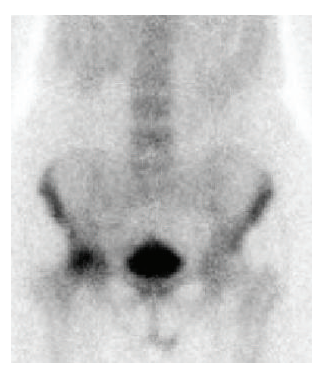

(c)

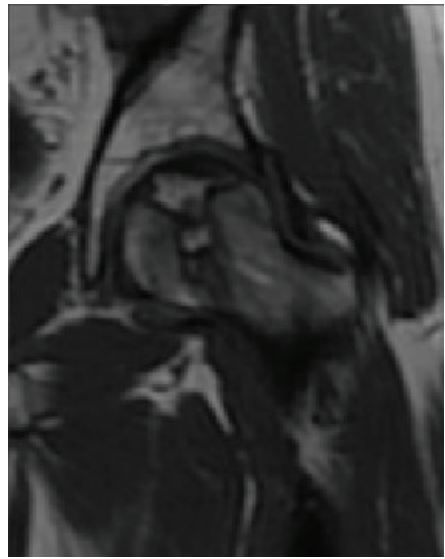

(f)

FIGURE 8: (a) X-ray of a patient with transient osteoporosis of the left hip showing osteoporosis. (b) Coronal stir imaging showing diffuse edema. Scintigraphy (c), sagittal T1 (d), and coronal PD fat sat (e) of a patient with a subchondral fracture of the femoral head with convex shape to the articular surface. Coronal T1 (f) of a patient with avascular necrosis of the femoral head.

been stressed after the term femoral acetabular impingement was coined in 2003 [33]. Growing interest has been focused in accurate diagnosis of the acetabular and femoral morphological abnormalities that may lead to early osteoarthritis.

MR imaging is considered paramount to these objectives, mainly when surgery is considered, due to the ability of MRI to portray the whole section of the femoral neck surface, as well as to image the labrum and articular cartilage.

Diagnosis of impingement can only be achieved if, besides imaging findings, there are also clinical symptoms and positive impingement maneuvers [34].

Most of the angles and measurements described in the plain radiograph section can be accurately reproduced on MRI. In addition, the superiority of MRI resolution with intra-articular contrast allows detection of labral and chondral abnormalities that may influence the choice of medical, percutaneous, or surgical management (Figure 9).

MR arthrography has proven superior in accuracy when compared to native MR imaging. It is considered the best technique to assess the labrum. Knowledge of the normal variable morphology of the labrum helps to differentiate tears from normal variants. A triangular shape is most commonly seen in $66 \%$ of asymptomatic volunteers, but round, flattened, and absent labra can also be found in asymptomatic populations [35]. MR arthrography has demonstrated sensitivity over $90 \%$ and specificity close to $100 \%$ in detecting labral tears. Loose bodies are demonstrated as filling defects surrounded by the hyperintense gadolinium $[36,37]$.

Association between labral tears and chondral damage has been demonstrated. This underscores the interaction between cartilage and labrum damage in the progression of osteoarthritis [38]. Chondral damage to the posteroinferior part of the acetabulum as a contrecoup lesion occurs in approximately one-third of pincer cases secondary to persistent abutment on the anterior part of the joint leading to a slight posteroinferior subluxation. This is considered a bad prognosis sign [39].

MR arthrography can also demonstrate ligamentum teres rupture or capsular laxity, which are debated causes of microinstability of the hip [40]. Elongation of the capsule or injury to the iliofemoral ligament or labrum may be secondary to microtrauma in athletes [41]. MR can demonstrate abnormalities in these cases, such as increased joint volume or a ligamentum teres tear (Figure 9).

Intra-articular osseous causes of pain include several conditions: avascular necrosis (AVN), transient osteoporosis of the hip (TOH), tumors, and stress or insufficiency fractures. All these entities may present with a pattern of bone marrow edema characterized by decreased signal intensity on T1 weighted images and increased signal intensity on fluid sensitive sequences, such as fat saturated T2-weighted or STIR images. When there is no evidence of a focal lesion 


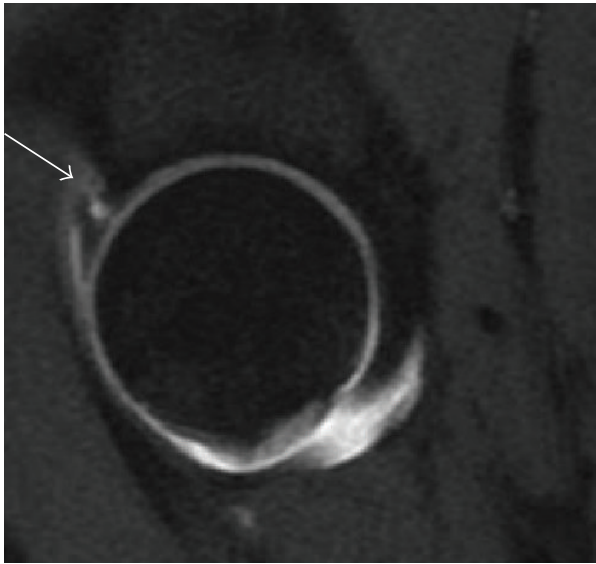

(a)

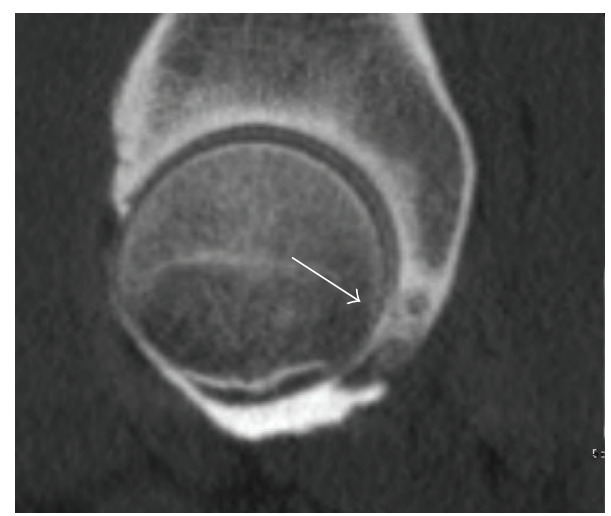

(c)

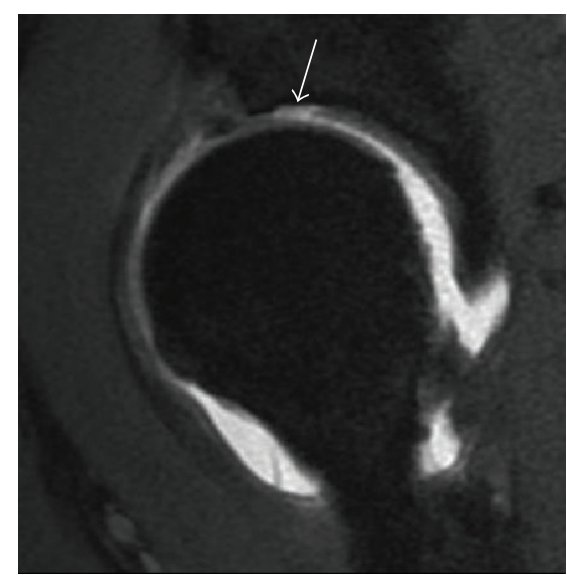

(b)

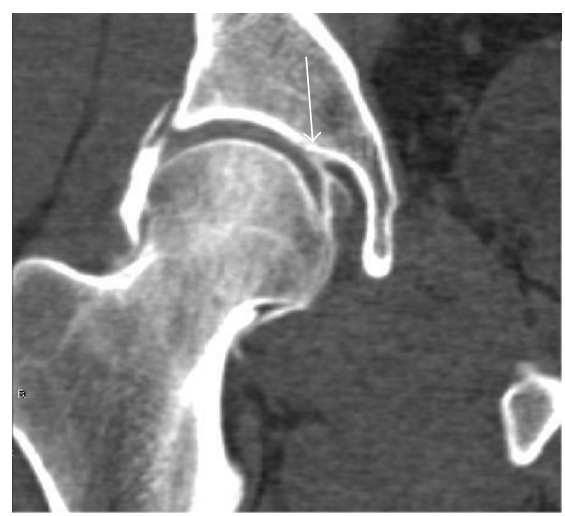

(d)

FIGURE 9: Sagittal T1 weighted images showing anterosuperior labral tear (a) and chondral lesion (b). Sagittal CT-arthrography showing posteroinferior chondral injury (c) and coronal CT-arthrography (d) showing ligamentum teres tear.

associated with the edema pattern, TOH is suspected [42]. When a band of low intensity is seen inside the edematous area, the shape and length of this band become important. It is generally convex to the articular surface in the case of subchondral stress or insufficiency fractures, whereas it is concave, circumscribing all of the necrotic segment, in cases of AVN. When doubts do persist, gadolinium-enhanced MRI tends to show that the proximal portion beyond the band is enhanced in fractures but is not in AVN [43].

MRI has been shown to have $100 \%$ sensitivity and specificity in prospective studies of occult hip fractures. These fractures were diagnosed by bone marrow edema and a low signal fracture line, mainly on T1 or T2 weighted images [44] (Figure 10).

In synovial proliferative disorders, MRI demonstrates synovial hypertrophy. In the case of PVNS, characteristic foci of low signal intensity related to hemosiderin deposition are better seen on gradient echo T2* images [45] (Figure 7). In the case of synovial osteochondromatosis, the synovial hypertrophy is accompanied by intermediate signal cartilaginous loose bodies and/or low signal calcified loose bodies [46].

\section{Computed Tomography}

Due to radiation concerns, CT has been relegated after MRI in the study of intra-articular causes of hip pain. The only exception where CT is considered superior to MRI is in bone tumors, because of its ability in characterizing matrix calcifications, and in depicting the anatomy of acute traumatic fractures. Typical matrix calcifications include the following: (a) osteoid mineralization, like a dense cloud, (b) chondroid calcification, reproducing a punctate popcorn pattern, or (c) fibrous calcification, ground glass-like appearance. There are also tumors that typically do not show matrix calcification. CT is also used for accurate localization of the nidus in osteoid osteomas and this must be differentiated from Brodie's abscess or a stress fracture [47]. The current standard treatment of osteoid osteoma is percutaneous radiofrequency ablation and this is usually performed under CT guidance [48].

Quite often, CT is widely available unlike MRI, especially in the acute setting. CT is performed in this setting when doubt about the existence of a fracture persists following plain radiograph. Modern multidetector computed tomography 


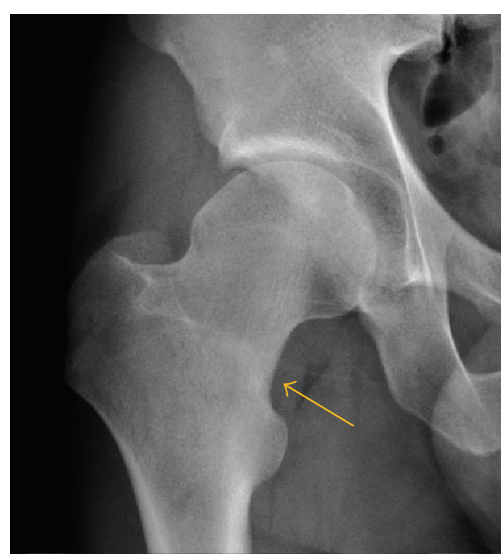

(a)

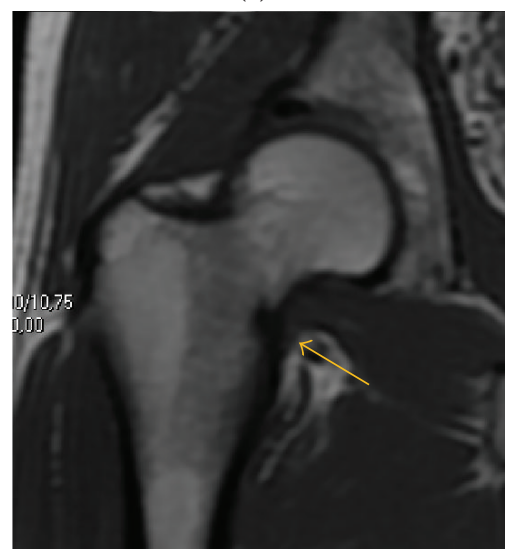

(c)

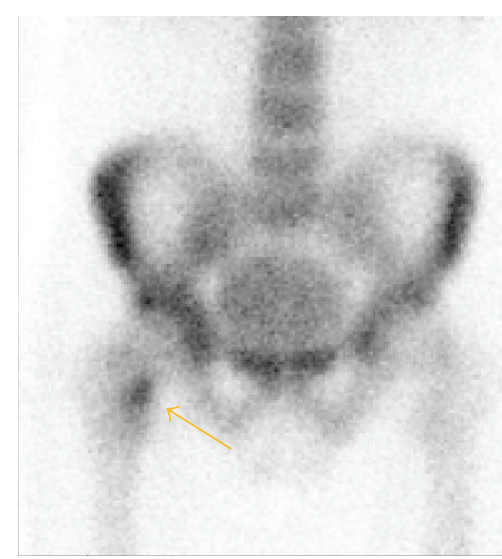

(b)

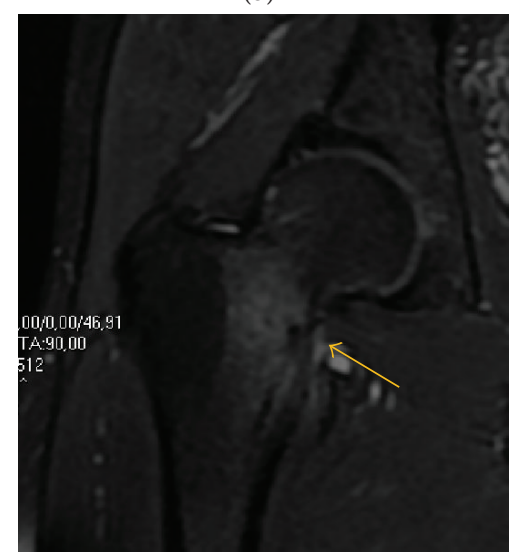

(d)

FIGURE 10: Stress femoral neck fracture in a young athlete barely visible in X-ray film as a sclerotic line (arrow) (a). Tc 99 scintigraphy shows a band of uptake (b), while T1 (c) and DP fat saturated (d) weighted MR images showed the fracture line and a pattern of edema.

(MDCT) shows results comparable with MRI for detecting occult fractures [49].

Due to the submillimeter resolution of MDCT arthrography, many authors consider this technique complementary to MR arthrography. It may even have superior sensitivity in detecting cartilage pathology, but lesser detecting labral tears $[50,51]$.

CT can also be used to obtain accurate measurement of the femoral version and torsion. The femoral version is measured by an angle formed between a line through the femoral head-neck axis and another horizontal line drawn between both ischial tuberosities. Normal values range between 5 and $25^{\circ}$. Retroversion is considered abnormal.

Femoral torsion is the angle between a line along the femoral head and neck axis and a second line that is touching the posterior border of both femoral condyles. The normal value at birth is approximately $32^{\circ}$ and decreases gradually with age. In adults, the normal value ranges from $10^{\circ}$ to $20^{\circ}$ [52].

\section{Ultrasound}

Ultrasound is the first-choice technique for diagnosis of newborns hip dysplasia. In experienced hands with appropriate technology, ultrasound can also be useful during the first year of life [53]. Some European healthcare systems encourage universal ultrasound screening in neonates between the sixth and eighth weeks. Although it shows higher initial costs caused, it leads to significant reduction in the total number and overall costs of dysplastic hips undergoing operative and nonoperative treatment $[54,55]$.

Ultrasound allows categorizing pediatric hips, according to Graf's criteria, in four main types: normal, immature, and dysplastic (subluxed and dislocated) [56]. This classification is based on measurements of the acetabular inclination angle (alpha), cartilage roof angle (beta), and infant age [57]. The femoral head coverage can also be determined by dividing the length of the femoral head covered by the acetabular fossa and the diameter of the femoral head. Its lower normal limits are $47 \%$ for boys and $44 \%$ for girls [58] (Figure 11).

In a recent study, including newborns with high clinical suspicion for DDH [59] (Ortolani/Barlow test, asymmetry in abduction of $20^{\circ}$ or greater, breech presentation, leg-length discrepancy, and first-degree relative treated for DDH), hip sonography led to a change in clinical diagnosis in 52\% of hips and to a change in management plan in $32 \%$ of hips. It obviated further follow-up in $23 \%$, strengthening its role as an important technique reassuring the clinical diagnosis [60]. 


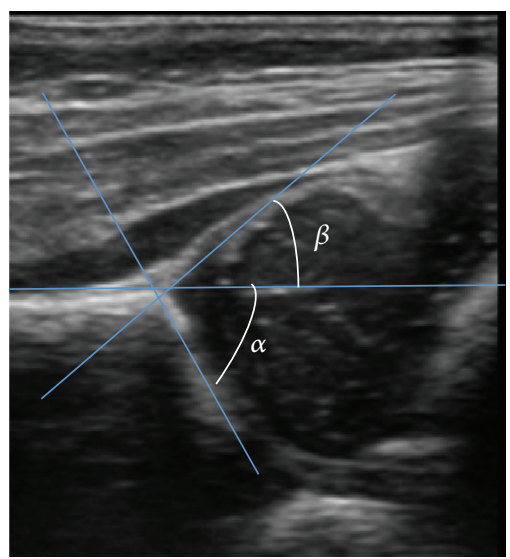

(a)

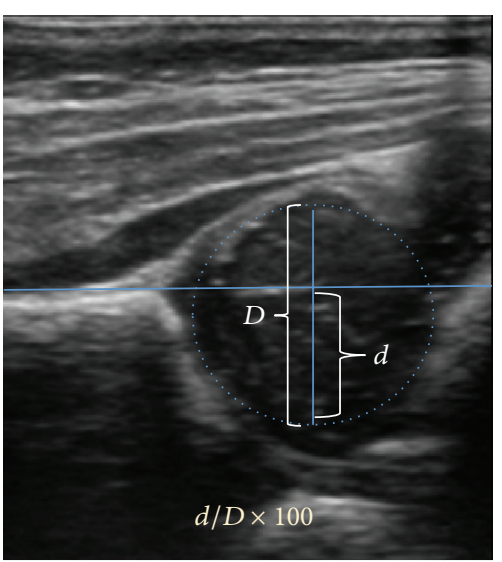

(b)

FIGURE 11: (a) Useful ultrasound measures in neonatal hip sonography, alpha and beta angles. (b) Measurement of femoral head coverage.

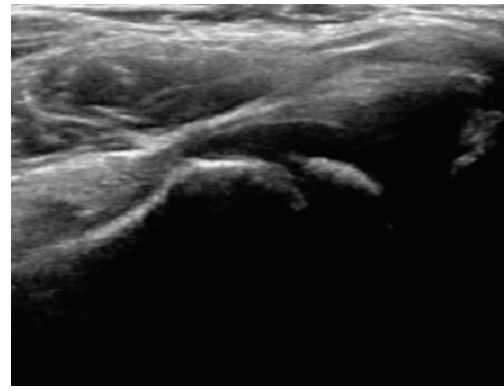

(a)

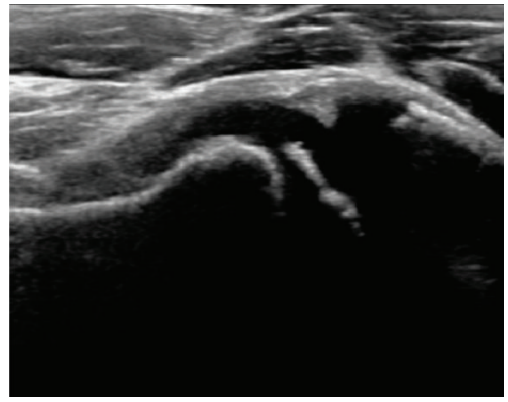

(c)

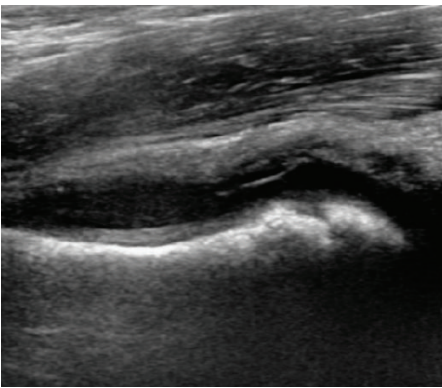

(b)

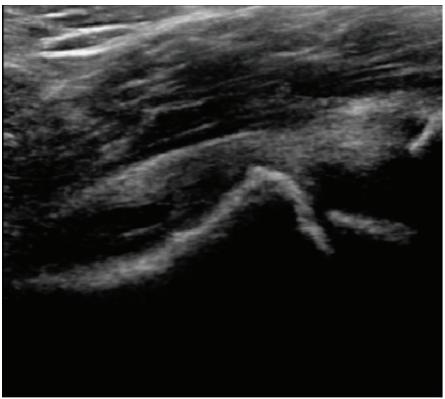

(d)

FIGURE 12: (a) Normal ultrasound appearance of the femoral head-neck junction. (b) Joint effusion in transient synovitis of the hip. (c) Flattening of the femoral head in a patient with Perthes disease. (d) Step in the femoral head-neck junction in a patient with SCFE.

During childhood, ultrasound is a quick method to assess hip pain and quite often may be used to avoid use of irradiating techniques, such as radiography or CT. Ultrasound allows evaluation of joint effusion, synovial thickening and neovascularity, the bone/cartilage contour, and the femoral head-neck alignment. Although sonography is extremely sensitive in detecting increased synovial fluid, it is nonspecific and cannot be used with accuracy to determine the type of fluid. Transient synovitis of the hip, despite being the most frequent cause of pain in children between 3 and 10 years, remains a diagnosis of exclusion. It usually shows anechoic fluid, but echogenic fluid can also be found [61]. The effusion is considered pathologic when it is measured at $>2 \mathrm{~mm}$ in thickness [62]. The differential diagnosis is wide, including osteomyelitis, septic arthritis, primary or metastatic lesions, LCPD, and SCFE [63]. Discrimination from septic arthritis is challenging, often requiring joint aspiration. In septic arthritis, US is able to demonstrate a hip joint effusion, synovial thickening, and cartilage damage, although the appearances are nonspecific [64].

A step between the head and the physis can be detected in children with SCFE, while abnormalities in the femoral head 
contour may suggest the presence of LCPD. In both cases, radiographs are mandatory to confirm diagnosis and severity [65] (Figure 12).

In adults, the most common application for US is to detect tendon or muscle injuries, effusion or synovitis within the hip joint or its adjacent bursae [66]. Joint effusions may be due to many intra-articular processes and this may need another imaging technique to achieve a specific diagnosis.

\section{Nuclear Medicine}

Bone scanning in patients with hip pain can be complementary to other imaging studies, mainly in indeterminate bone lesions to clarify whether it is an active lesion with abnormal radiotracer accumulation. Nevertheless, MRI has replaced scintigraphy in the diagnosis of most of these conditions. An example is stress or insufficiency fractures: increased uptake is usually present in around $80 \%$ of fractures within $24 \mathrm{~h}$, and $95 \%$ of fractures reveal activity by $72 \mathrm{~h}$ following trauma [67], showing an overall sensitivity of $93 \%$ and specificity of $95 \%$ [68]. MRI is superior to bone scans in terms of sensitivity (99\%-100\%) and specificity (100\%) [69, 70]. Moreover, a bone scan does not provide detailed anatomical location of the fracture, and further imaging is usually required [71].

\section{Conflict of Interests}

The authors declare that there is no conflict of interests regarding the publication of this paper.

\section{References}

[1] L. M. Tibor and J. K. Sekiya, "Differential diagnosis of pain around the hip joint," Arthroscopy, vol. 24, no. 12, pp. 1407-1421, 2008.

[2] E. Maslowski, W. Sullivan, J. F. Harwood et al., "The diagnostic validity of hip provocation maneuvers to detect intra-articular hip pathology," $P M$ \& R, vol. 2, no. 3, pp. 174-181, 2010.

[3] D. Tönnis, "Normal values of the hip joint for the evaluation of X-rays in children and adults," Clinical Orthopaedics and Related Research, vol. 119, pp. 39-47, 1976.

[4] H. Omeroğlu, A. Kaya, and B. Güçlü, "Evidence-based current concepts in the radiological diagnosis and follow-up of developmental dysplasia of the hip," Acta Orthopaedica et Traumatologica Turcica, vol. 41, supplement 1, pp. 14-18, 2007.

[5] D. Tönnis, Congenital Dysplasia and Dislocation of the Hip in Children and Adults, Springer, Berlin, Germany, 1987.

[6] U. Narayanan, K. Mulpuri, W. N. Sankar, N. M. P. Clarke, H. Hosalkar, and C. T. Price, "Reliability of a new radiographic classification for developmental dysplasia of the hip," Journal of Pediatric Orthopaedics, vol. 35, no. 5, pp. 478-484, 2015.

[7] J. R. Dwek, C. B. Chung, and D. J. Sartoris, "Developmental dysplasia of the hip," in Diagnosis of Bone and Joint Disorders, D. Resnick, Ed., pp. 4355-4381, Saunders, Philadelphia, Pa, USA, 4th edition, 2002.

[8] E. J. Eyring, D. R. Bjornson, and C. A. Peterson, "Early diagnostic and prognostic signs in Legg-Calvé-Perthes disease," American Journal of Roentgenology, vol. 93, pp. 382-387, 1965.
[9] C. Gigante, P. Frizziero, and S. Turra, "Prognostic value of Catterall and Herring classification in Legg-Calvé-Perthes disease: follow-up to skeletal maturity of 32 patients," Journal of Pediatric Orthopaedics, vol. 22, no. 3, pp. 345-349, 2002.

[10] J. A. Herring, H. T. Hui, and R. Browne, "Legg-Calvé-Perthes disease. Part I: classification of radiographs with use of the modified lateral pillar and stulberg classifications," The Journal of Bone \& Joint Surgery, vol. 86, no. 10, pp. 2103-2120, 2004.

[11] J. A. Herring, T. K. Hui, and R. Browne, "Legg-Calvé-Perthes disease. Part II: prospective multicenter study of the effect of treatment on outcome," The Journal of Bone \& Joint SurgeryAmerican Volume, vol. 86, no. 10, pp. 2121-2134, 2004.

[12] R. T. Loder, "Correlation of radiographic changes with disease severity and demographic variables in children with stable slipped capital femoral epiphysis," Journal of Pediatric Orthopaedics, vol. 28, no. 3, pp. 284-290, 2008.

[13] J. J. Nepple, C. L. Lehmann, J. R. Ross, P. L. Schoenecker, and J. C. Clohisy, "Coxa profunda is not a useful radiographic parameter for diagnosing pincer-type femoroacetabular impingement," The Journal of Bone \& Joint Surgery, vol. 95, no. 5, pp. 417-423, 2013.

[14] V. B. Vare Jr., "The anatomy of the pelvic tear figure," The Journal of Bone \& Joint Surgery-American Volume, vol. 34, no. 1, pp. 167-169, 1952.

[15] A. Troelsen, L. Rømer, S. Kring, B. Elmengaard, and K. Søballe, "Assessment of hip dysplasia and osteoarthritis: variability of different methods," Acta Radiologica, vol. 51, no. 2, pp. 187-193, 2010.

[16] D. R. Pedersen, C. A. Lamb, L. A. Dolan, H. M. Ralston, S. L. Weinstein, and J. A. Morcuende, "Radiographic measurements in developmental dysplasia of the hip: reliability and validity of a digitizing program," Journal of Pediatric Orthopaedics, vol. 24, no. 2, pp. 156-160, 2004.

[17] A. Ozcelik, H. Omeroglu, U. Inan, and S. Seber, "Center-edge angle values in normal hips of children and adults in Turkish population," Journal of Arthroplasty Arthroscopic Surgery, vol. 12, pp. 115-119, 2001.

[18] L. B. Laborie, T. G. Lehmann, I. Ø. Engesæter, L. B. Engesæter, and K. Rosendahl, "Is a positive femoroacetabular impingement test a common finding in healthy young adults?" Clinical Orthopaedics and Related Research, vol. 471, no. 7, pp. 2267-2277, 2013.

[19] M. Ezoe, M. Naito, and T. Inoue, "The prevalence of acetabular retroversion among various disorders of the hip," The Journal of Bone \& Joint Surgery-American Volume, vol. 88, no. 2, pp. 372-379, 2006.

[20] C. Diaz-Ledezma, T. Novack, O. Marin-Peña, and J. Parvizi, "The relevance of the radiological signs of acetabular retroversion among patients with femoroacetabular impingement," Bone and Joint Journal B, vol. 95, no. 7, pp. 893-899, 2013.

[21] K. K. Gosvig, S. Jacobsen, S. Sonne-Holm, and P. Gebuhr, "The prevalence of cam-type deformity of the hip joint: a survey of 4151 subjects of the Copenhagen Osteoarthritis study," Acta Radiologica, vol. 49, no. 4, pp. 436-441, 2008.

[22] H. Eijer, M. Leunig, M. N. Mahomed, and R. Ganz, "Crosstable lateral radiograph for screening of anterior femoral head-neck offset in patients with femoro-acetabular impingement," Hip International, vol. 11, pp. 37-41, 2001. 
[23] T. Y. Kuo, J. G. Skedros, and R. D. Bloebaum, "Measurement of femoral anteversion by biplane radiography and computed tomography imaging: comparison with an anatomic reference," Investigative Radiology, vol. 38, no. 4, pp. 221-229, 2003.

[24] J. C. Clohisy, J. C. Carlisle, P. E. Beaulé et al., "A systematic approach to the plain radiographic evaluation of the young adult hip," The Journal of Bone \& Joint Surgery-American Volume, vol. 90, supplement 4, pp. 47-66, 2008.

[25] H. K. Ea and F. Lioté, "Calcium pyrophosphate dihydrate and basic calcium phosphate crystalinduced arthropathies: update on pathogenesis, clinical features, and therapy," Current Rheumatology Reports, vol. 6, no. 3, pp. 221-227, 2004.

[26] A. Pourbagher, M. A. Pourbagher, L. Savas et al., "Epidemiologic, clinical, and imaging findings in brucellosis patients with osteoarticular involvement," American Journal of Roentgenology, vol. 187, no. 4, pp. 873-880, 2006.

[27] M. A. Bhimani, J. F. Wenz, and F. J. Frassica, "Pigmented villonodular synovitis: keys to early diagnosis," Clinical Orthopaedics and Related Research, vol. 386, pp. 197-202, 2001.

[28] R. P. Ficat, "Idiopathic bone necrosis of the femoral head. Early diagnosis and treatment," The Journal of Bone \& Joint SurgeryBritish Volume, vol. 67, no. 1, pp. 3-9, 1985.

[29] R. Chana, A. Noorani, N. Ashwood, U. Chatterji, J. Healy, and P. Baird, "The role of MRI in the diagnosis of proximal femoral fractures in the elderly," Injury, vol. 37, no. 2, pp. 185-189, 2006.

[30] W. J. Yang, S. A. Im, G.-Y. Lim et al., "MR imaging of transient synovitis: differentiation from septic arthritis," Pediatric Radiology, vol. 36, no. 11, pp. 1154-1158, 2006.

[31] J. R. Dillman and R. J. Hernandez, "MRI of Legg-Calvé-Perthes disease," American Journal of Roentgenology, vol. 193, no. 5, pp. 1394-1407, 2009.

[32] C. Baunin, D. Sanmartin-Viron, F. Accadbled et al., "Prognosis value of early diffusion MRI in Legg Perthes Calvé disease," Orthopaedics and Traumatology: Surgery \& Research, vol. 100, no. 3, pp. 317-321, 2014.

[33] R. Ganz, J. Parvizi, M. Beck, M. Leunig, H. Nötzli, and K. A. Siebenrock, "Femoroacetabular impingement: a cause for osteoarthritis of the hip," Clinical Orthopaedics and Related Research, vol. 417, pp. 112-120, 2003.

[34] M. Lequesne and L. Bellaïche, "Anterior femoroacetabular impingement: an update," Joint Bone Spine, vol. 79, no. 3, pp. 249-255, 2012.

[35] F. E. Lecouvet, B. C. Vande Berg, J. Malghem et al., "MR imaging of the acetabular labrum: variations in 200 asymptomatic hips," American Journal of Roentgenology, vol. 167, no. 4, pp. 10251028, 1996.

[36] G. A. Toomayan, W. R. Holman, N. M. Major, S. M. Kozlowicz, and T. P. Vail, "Sensitivity of MR arthrography in the evaluation of acetabular labral tears," American Journal of Roentgenology, vol. 186, no. 2, pp. 449-453, 2006.

[37] B. A. Freedman, B. K. Potter, P. A. Dinauer, J. R. Giuliani, T. R. Kuklo, and K. P. Murphy, "Prognostic value of magnetic resonance arthrography for Czerny stage II and III acetabular labral tears," Arthroscopy, vol. 22, no. 7, pp. 742-747, 2006.

[38] J. C. McCarthy, P. C. Noble, M. R. Schuck, J. Wright, and J. Lee, "The Otto E. Aufranc Award: the role of labral lesions to development of early degenerative hip disease," Clinical Orthopaedics and Related Research, vol. 393, pp. 25-37, 2001.
[39] M. Tannast, K. A. Siebenrock, and S. E. Anderson, "Femoroacetabular impingement: radiographic diagnosis-what the radiologist should know," American Journal of Roentgenology, vol. 188, no. 6, pp. 1540-1552, 2007.

[40] L. Cerezal, A. Kassarjian, A. Canga et al., "Anatomy, biomechanics, imaging, and management of ligamentum teres injuries," RadioGraphics, vol. 30, no. 6, pp. 1637-1651, 2010.

[41] B. Shu and M. R. Safran, "Hip instability: anatomic and clinical considerations of traumatic and atraumatic instability," Clinics in Sports Medicine, vol. 30, no. 2, pp. 349-367, 2011.

[42] F. Ruiz-Santiago, F. C. Pérez, and J. M. T. Fernández, "Clinical and radiological follow-up until its resolution of a case of subchondral fracture of the femoral head," European Journal of Radiology Extra, vol. 61, no. 3, pp. 105-108, 2007.

[43] S. Ikemura, T. Yamamoto, G. Motomura, Y. Nakashima, T. Mawatari, and Y. Iwamoto, "MRI evaluation of collapsed femoral heads in patients 60 years old or older: differentiation of subchondral insufficiency fracture from osteonecrosis of the femoral head," American Journal of Roentgenology, vol. 195, no. 1, pp. W63-W68, 2010.

[44] P. D. Evans, C. Wilson, and K. Lyons, "Comparison of MRI with bone scanning for suspected hip fracture in elderly patients," The Journal of Bone \& Joint Surgery, vol. 76, no. 1, pp. 158-159, 1994.

[45] C. Fang and J. Teh, "Imaging of the hip," Imaging, vol. 15, no. 4, pp. 205-216, 2003.

[46] S. H. Kim, S. J. Hong, J. S. Park et al., "Idiopathic synovial osteochondromatosis of the hip: radiographic and MR appearances in 15 patients," Korean Journal of Radiology, vol. 3, no. 4, pp. 254259, 2002.

[47] J. W. Chai, S. H. Hong, J.-Y. Choi et al., "Radiologic diagnosis of osteoid osteoma: from simple to challenging findings," RadioGraphics, vol. 30, no. 3, pp. 737-749, 2010.

[48] F. Ruiz Santiago, M. del Mar Castellano García, L. Guzmán Álvarez, J. L. Martínez Montes, M. Ruiz García, and J. M. Tristán Fernández, "Percutaneous treatment of bone tumors by radiofrequency thermal ablation," European Journal of Radiology, vol. 77, no. 1, pp. 156-163, 2011.

[49] S. K. Gill, J. Smith, R. Fox, and T. J. S. Chesser, "Investigation of occult hip fractures: the use of CT and MRI," The Scientific World Journal, vol. 2013, Article ID 830319, 4 pages, 2013.

[50] T. Nishii, H. Tanaka, K. Nakanishi, N. Sugano, H. Miki, and H. Yoshikawa, "Fat-suppressed 3D spoiled gradient-echo MRI and MDCT arthrography of articular cartilage in patients with hip dysplasia," American Journal of Roentgenology, vol. 185, no. 2, pp. 379-385, 2005.

[51] E. Perdikakis, T. Karachalios, P. Katonis, and A. Karantanas, "Comparison of MR-arthrography and MDCT-arthrography for detection of labral and articular cartilage hip pathology," Skeletal Radiology, vol. 40, no. 11, pp. 1441-1447, 2011.

[52] M. A. Westcott, M. C. Dynes, E. M. Remer, J. S. Donaldson, and L. S. Dias, "Congenital and acquired orthopedic abnormalities in patients with myelomeningocele," RadioGraphics, vol. 12, no. 6, pp. 1155-1173, 1992.

[53] R. M. Schwend, P. Schoenecker, B. S. Richards, J. M. Flynn, and M. Vitale, "Screening the newborn for developmental dysplasia of the hip. Now what do we do?" Journal of Pediatric Orthopaedics, vol. 27, no. 6, pp. 607-610, 2007. 
[54] M. Thaler, R. Biedermann, J. Lair, M. Krismer, and F. Landauer, "Cost-effectiveness of universal ultrasound screening compared with clinical examination alone in the diagnosis and treatment of neonatal hip dysplasia in Austria," The Journal of Bone \& Joint Surgery-British Volume, vol. 93, no. 8, pp. 1126-1130, 2011.

[55] A. Gray, D. Elbourne, C. Dezateux, A. King, A. Quinn, and F. Gardner, "Economic evaluation of ultrasonography in the diagnosis and management of developmental hip dysplasia in the United Kingdom and Ireland," The Journal of Bone \& Joint Surgery-American Volume, vol. 87, no. 11, pp. 2472-2479, 2005.

[56] R. Graf, "Classification of hip joint dysplasia by means of sonography," Archives of Orthopaedic and Traumatic Surgery, vol. 102, no. 4, pp. 248-255, 1984.

[57] R. Graf, "Hip sonography: 20 years' experience and results," HIP International, vol. 17, supplement 5, pp. S8-S14, 2007.

[58] T. Terjesen, T. Bredland, and V. Berg, "Ultrasound for hip assessment in the newborn," The Journal of Bone \& Joint Surgery, vol. 71, no. 5, pp. 767-773, 1989.

[59] A. Roposch, L. Q. Liu, F. Hefti, N. M. P. Clarke, and J. H. Wedge, "Standardized diagnostic criteria for developmental dysplasia of the hip in early infancy," Clinical Orthopaedics and Related Research, vol. 469, no. 12, pp. 3451-3461, 2011.

[60] E. Ashby and A. Roposch, "Diagnostic yield of sonography in infants with suspected hip dysplasia: diagnostic thinking efficiency and therapeutic efficiency," American Journal of Roentgenology, vol. 204, no. 1, pp. 177-181, 2015.

[61] G. J. Marchal, M. T. van Holsbeeck, M. Raes et al., "Transient synovitis of the hip in children: role of US," Radiology, vol. 162, no. 3, pp. 825-828, 1987.

[62] W. K. Rohrschneider, G. Fuchs, and J. Tröger, "Ultrasonographic evaluation of the anterior recess in the normal hip: a prospective study on 166 asymptomatic children," Pediatric Radiology, vol. 26, no. 9, pp. 629-634, 1996.

[63] S. U. Fischer and T. F. Beattie, "The limping child: epidemiology, assessment, and outcome," The Journal of Bone \& Joint SurgeryBritish Volume, vol. 81, no. 6, pp. 1029-1034, 1999.

[64] M. M. Zamzam, "The role of ultrasound in differentiating septic arthritis from transient synovitis of the hip in children," Journal of Pediatric Orthopaedics-Part B, vol. 15, no. 6, pp. 418-422, 2006.

[65] C. E. Konstantoulakis, D. V. Petratos, M. Kokkinakis, E. Morakis, and J. N. Anastasopoulos, "Initial diagnostic approach of the irritable hip in childhood: is ultrasound really useful ?" Acta Orthopaedica Belgica, vol. 77, no. 5, pp. 603-608, 2011.

[66] C. Martinoli, I. Garello, A. Marchetti et al., "Hip ultrasound," European Journal of Radiology, vol. 81, no. 12, pp. 3824-3831, 2012.

[67] P. Matin, "The appearance of bone scans following fractures, including immediate and long-term studies," Journal of Nuclear Medicine, vol. 20, no. 12, pp. 1227-1231, 1979.

[68] L. E. Holder, C. Schwarz, P. G. Wernicke, and R. H. Michael, "Radionuclide bone imaging in the early detection of fractures of the proximal femur (hip): multifactorial analysis," Radiology, vol. 174 , no. 2, pp. 509-515, 1990.

[69] M. C. Cabarrus, A. Ambekar, Y. Lu, and T. M. Link, "MRI and CT of insufficiency fractures of the pelvis and the proximal femur," American Journal of Roentgenology, vol. 191, no. 4, pp. 995-1001, 2008.
[70] S. J. Rubin, J. D. Marquardt, R. H. Gottlieb, S. P. Meyers, S. M. S. Totterman, and R. E. O'Mara, "Magnetic resonance imaging: a cost-effective alternative to bone scintigraphy in the evaluation of patients with suspected hip fractures," Skeletal Radiology, vol. 27, no. 4, pp. 199-204, 1998.

[71] O. Lubovsky, M. Liebergall, Y. Mattan, Y. Weil, and R. Mosheiff, "Early diagnosis of occult hip fractures: MRI versus CT scan," Injury, vol. 36, no. 6, pp. 788-792, 2005. 


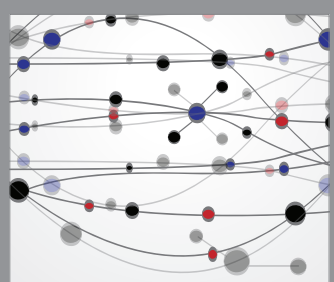

The Scientific World Journal
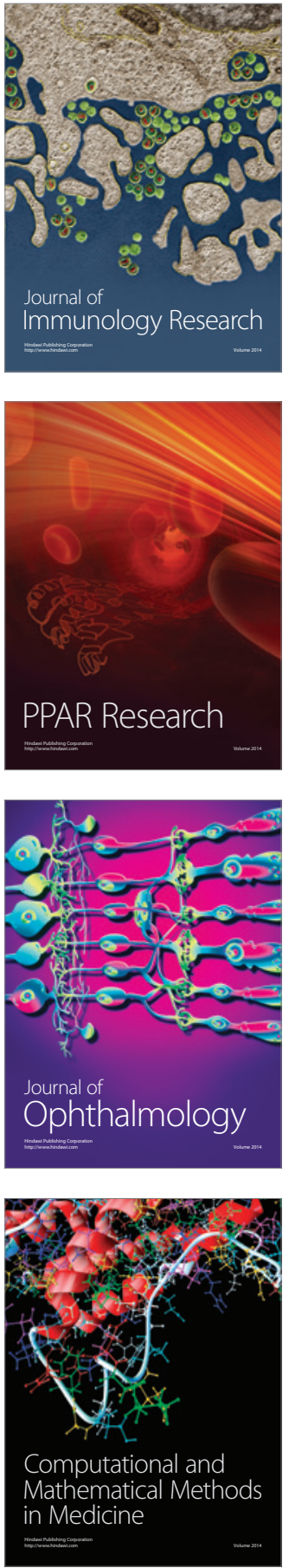

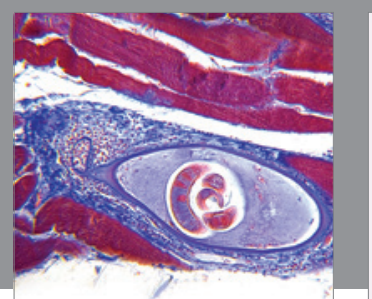

Gastroenterology Research and Practice

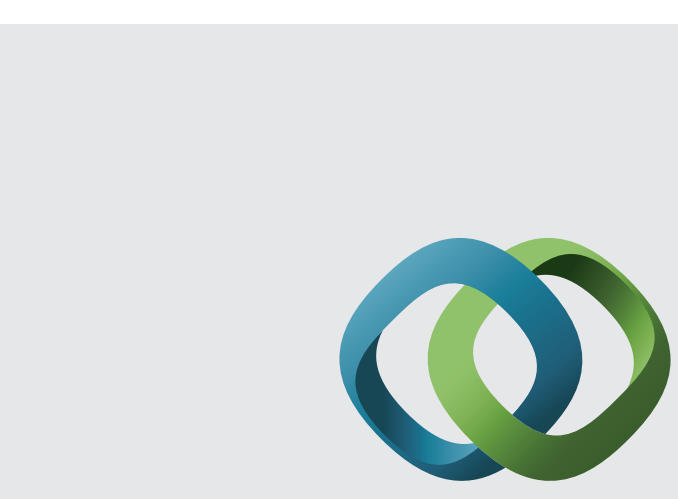

\section{Hindawi}

Submit your manuscripts at

http://www.hindawi.com
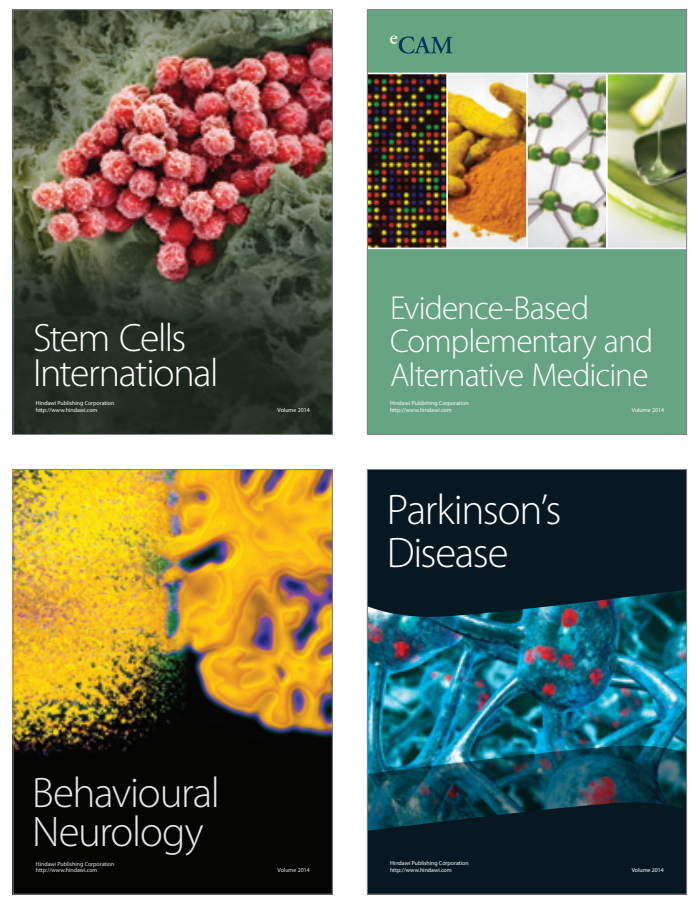
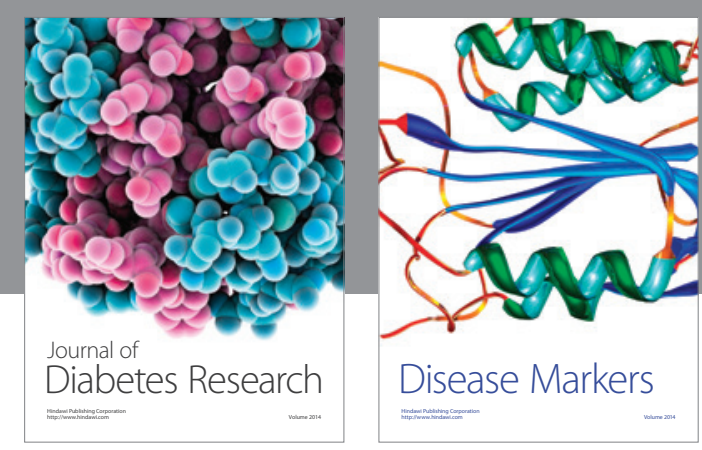

Disease Markers
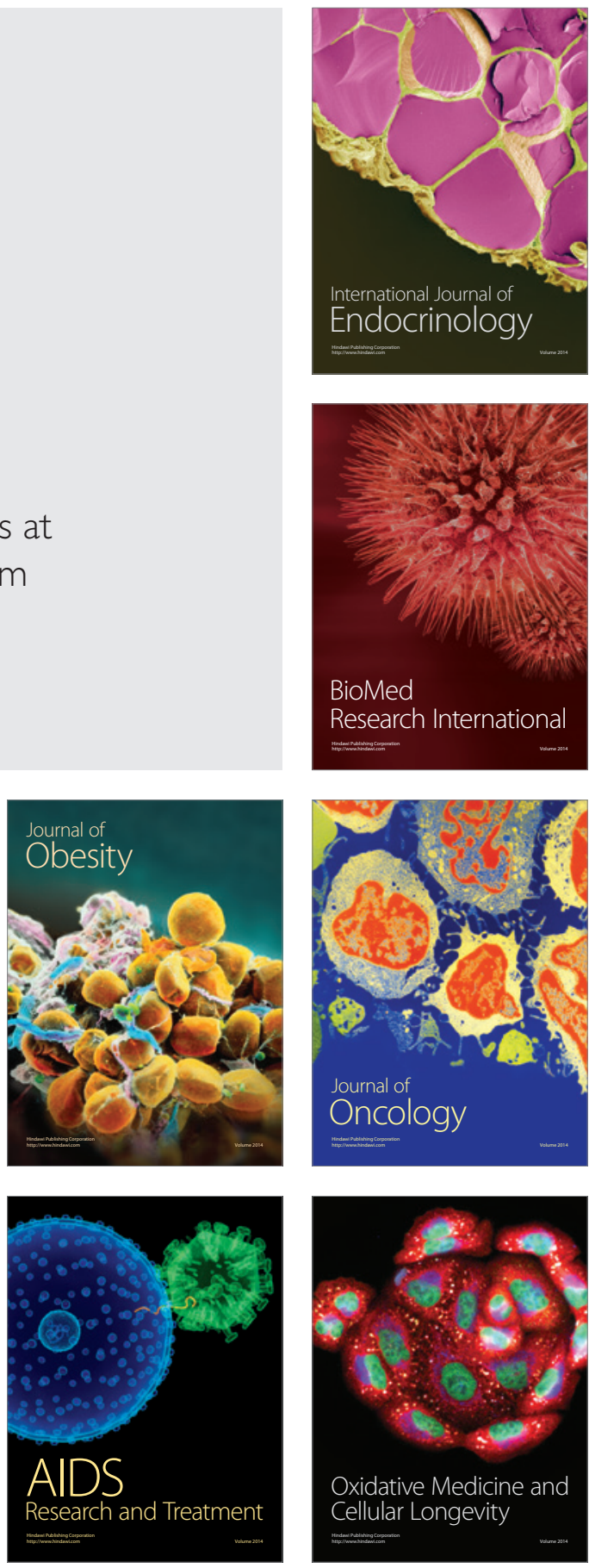